\title{
Predictors of psychiatric rehospitalization among elderly
}

\section{patients [version 1; peer review: 3 approved]}

\author{
Chun Yin Terry Wong
}

Department of Psychiatry, Pamela Youde Nethersole Eastern Hospital, Hong Kong, Hong Kong

\author{
V1 First published: 30 Sep 2015, 4:926 \\ https://doi.org/10.12688/f1000research.7135.1 \\ Latest published: 30 Sep 2015, 4:926 \\ https://doi.org/10.12688/f1000research.7135.1
}

\begin{abstract}
The population of Hong Kong and the proportion of elderly people have been increasing rapidly. The aim of this retrospective cohort study is to determine predictive factors for psychiatric rehospitalization within 2 years among elderly patients who were discharged from psychiatric wards, in attempt to reduce their rehospitalization rate and to reintegrate them into the community. Patients aged 65 and over, who were discharged from psychiatric wards of Pamela Youde Nethersole Eastern Hospital from 1 March 2010 to 29 February 2012, were identified. Rehospitalization within 2 years after discharge was the primary outcome measure, and the time to rehospitalization was measured as the secondary outcome. Patients were subgrouped into readmitted and non-readmitted groups. Logistic regression and Cox regression analyses were applied to the potential predictive factors with odds ratios and hazard ratios obtained, respectively, for the significant findings. Kaplan-Meier survival curves were plotted for graphical representation of the study results in survival analysis. 368 individuals satisfying the study criteria were identified. The same four factors were shown to be significantly associated with rehospitalization in both multiple logistic regression and Cox regression survival analysis. Referral to other psychiatric disciplines upon discharge $(\mathrm{p}<0.001, \mathrm{OR}=0.325, \mathrm{HR}=0.405)$ was associated with a lower rehospitalization risk and correlated to a longer time to rehospitalization. History of suicidal behaviors $(\mathrm{p}<$ $0.001, \mathrm{OR}=4.906, \mathrm{HR}=3.161)$, history of violent behaviors $(p<0.001$, $\mathrm{OR}=5.443, \mathrm{HR}=3.935)$ and greater number of previous psychiatric admissions $(p<0.001, O R=1.250, H R=1.121)$ were associated with a higher rehospitalization risk and predicted earlier rehospitalization. The rehospitalization rate of elderly patients was $5.2 \%$ at 1 month, $9.5 \%$ at 3 months, $15.0 \%$ at 6 months, $17.1 \%$ at 1 year, $18.8 \%$ at 1.5 year and $20.9 \%$ at 2 years.
\end{abstract}

\section{Keywords}

risk factors, psychiatric, readmission, rehospitalization, elderly , geriatric

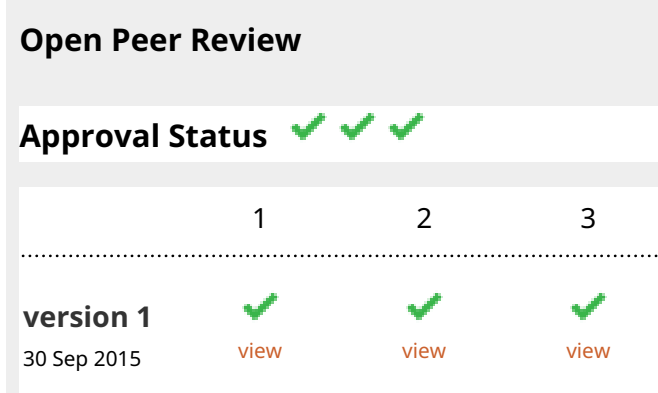

1. Xiao Shifu, Shanghai Jiaotong University School of Medicine, Shanghai, China

Wei Li, Shanghai Jiaotong University School of Medicine, Shanghai, China

2. W.Sue T Griffin, University of Arkansas for Medical Sciences, Little Rock, AR, USA

3. Jeffrey Braithwaite, Australian Institute of Health Innovation, Macquarie University, Sydney, Australia

Any reports and responses or comments on the article can be found at the end of the article. 
Corresponding author: Chun Yin Terry Wong (terrytwins85@gmail.com)

Competing interests: No competing interests were disclosed.

Grant information: The author declared that no grants were involved in supporting this work.

Copyright: $\odot 2015$ Wong CYT. This is an open access article distributed under the terms of the Creative Commons Attribution License, which permits unrestricted use, distribution, and reproduction in any medium, provided the original work is properly cited. Data associated with the article are available under the terms of the Creative Commons Zero "No rights reserved" data waiver (CC0 1.0 Public domain dedication).

How to cite this article: Wong CYT. Predictors of psychiatric rehospitalization among elderly patients [version 1; peer review: 3 approved] F1000Research 2015, 4:926 https://doi.org/10.12688/f1000research.7135.1

First published: 30 Sep 2015, 4:926 https://doi.org/10.12688/f1000research.7135.1 


\section{Background}

The population in Hong Kong and the proportion of elderly people are increasing rapidly. Pamela Youde Nethersole Eastern Hospital is a regional hospital under the Hospital Authority serving the eastern district of Hong Kong Island. The characteristics of elderly patients were different from that of general adults, for example, more of them suffered from cognitive disorders, they were more often hospitalized due to medical comorbidities, and they might require placement such as old age homes after discharge. Despite many psychiatric readmission studies were already available in the literature, surprisingly very few of them were targeted to elderly patients only.

Rehospitalization had been regarded as a useful indicator to measure quality of care provided by hospitals worldwide ${ }^{1,2}$. Since there are only a small number of elderly psychiatric rehospitalization studies available, studies involving elderly patents and patients of all ages (including the elderly) were reviewed. Socio-demographic factors that were identified as significant in previous studies included: age ${ }^{3-10}$, gender $^{5,8,11-14}$, ethnicity ${ }^{15}$, marital status ${ }^{14,16-20}$, education level ${ }^{13}$, and type of residence ${ }^{5,6,8,10,15,17,22,23}$. Clinical factors significantly associated with rehospitalization included: length of inpatient stay ${ }^{3,5,5,10,16,19,24,25}$, primary psychiatric diagnosis ${ }^{4,5,8,9,11,14,18,19,21,22,24,26}$, presence of psychiatric comorbidities ${ }^{4,17,27}$, presence of medical comorbidity ${ }^{21,27}$, cognitive impairment ${ }^{3,25}$, referral for aftercare services ${ }^{6,7,29,30}$, history of suicidal behaviors ${ }^{12}$, history of violence ${ }^{11,25,28,31}$ and number of previous psychiatric admissions $7,8,15,20,25,32,33$. Many of the articles adopted a retrospective design and involved psychiatric patients of all ages, while very few were specifically targeted elderly patients $^{20,22,27,33,34}$, and no such data was available for elderly psychiatric patients in Hong Kong. Therefore this study was conducted to identify risk factors in attempt to reduce rehospitalization, so mental health services could be utilized more effectively in view of of the increasing needs from the aging population.

\section{Methods}

The aim of this retrospective cohort study is to determine predictors for psychiatric rehospitalization over 2 years among elderly patients after they were discharged from psychiatric wards.

\section{Inclusion criteria}

Patients aged 65 and over, who were discharged from the psychiatric wards of Pamela Youde Nethersole Eastern Hospital from 1 March 2010 to 29 February 2012, formed the study population. For patients having repeated discharge episodes during the study period, only the first discharge episode was included as the index episode for that patient to avoid duplication of data from the same individuals.

\section{Exclusion criteria}

Patients who died during inpatient stay at the index episode, or had not received mental health care in any psychiatric clinics under the Hospital Authority after discharge, including those who were followed up by private psychiatrists or overseas psychiatric care systems, were excluded due to a lack of information to analyze their outcome.

\section{Data collection}

A list of patients satisfying the study criteria was generated from the Clinical Data Analysis and Reporting System (CDARS) of the Hospital Authority's Medical Records Office. The sociodemographic and clinical factors of each patient were determined by reviewing their medical records in the Hospital Authority's Clinical Management System (CMS) and case notes as charted by their respective case doctors. The CMS contained information on patients who had received health services under the Hospital Authority including their demographics, inpatient discharge summaries, outpatient consultation notes, physical or psychiatric diagnoses and medications that were prescribed. Data was collected electronically and entered in Microsoft Office Excel version 2010.

\section{Dependent variable}

Rehospitalization was defined as the primary outcome.

\section{Independent variables}

Socio-demographic factors included age (upon discharge), gender, ethnicity, marital status, education level and type of residence (upon discharge). Clinical factors included priority follow-up (PFU) status (see Appendix for more details), length of inpatient stay, primary psychiatric diagnosis (as determined from the medical coding with ICD-9-CM in CMS by respective case doctors), presence of psychiatric comorbidities (as reflected by more than one psychiatric diagnosis recorded in CMS in the index episode), number of chronic physical illnesses (which required regular outpatient follow ups by other specialties), MMSE scores, referral to other psychiatric disciplines upon discharge (including community psychiatric nurses, clinical psychologists, social workers or day hospital), history of suicidal behaviors (including suicide attempts and self-harm behaviors in lifetime), history of violent behaviors (in lifetime) and number of previous psychiatric admissions.

\section{Data analysis}

Null hypothesis

The null hypothesis was that none of the identified factors are associated with rehospitalization.

Univariate tests and multiple logistic regression analysis After descriptive statistical studies, univariate tests were conducted on all independent variables to identify possible significant factors for subsequent analysis. For categorical factors, a Chi-squared test was performed, and Fisher's exact test was conducted for factors with an expected cell count less than 5 . All the continuous factors in this study were not normally distributed as determined by the Shapiro-Wilk test and Mann-Whitney U test was conducted. Significant and marginally significant factors with a $p$ value of $<0.100$ identified in the univariate analysis were included in the subsequent multiple logistic regression analysis to identify significant factors (with a $p$ value of $<0.050$ ) predicting rehospitalization in 2 years after discharge.

\section{Survival analysis}

Survival analysis was further conducted to identify factors predicting earlier rehospitalization. The rehospitalization rates at different time points within the 2 years were calculated. Univariate analysis with simple Cox regression was performed to all variables. Those with a $p$ value of $<0.100$ were included in the subsequent multiple Cox regression analysis, to determine variables that significantly (with a $\mathrm{p}$ value of $<0.050$ ) correlated with time to rehospitalization. Kaplan-Meier survival curves were also plotted. 
The protocol of this study was approved by the Hospital Authority's Research Ethics Committee of Hong Kong East Cluster (Reference number: HKEC-2014-049). Data were analyzed through IBM Statistical Product and Service Solutions (SPSS) software version 22.

\section{Results}

\section{Dataset 1. Raw data of elderly patients discharged from psychiatric wards within the study period}

http://dx.doi.org/10.5256/f1000research.7135.d103399

The coding for each variable is explained in the top row. Blank rows correspond to the discharge episodes that were excluded according to the exclusion criteria.

Figure 1 presents the formation of the study population and separation into the subgroups. Of all 454 discharge episodes from psychiatric wards of Pamela Youde Nethersole Eastern Hospital with patients aged 65 and over from 1 March 2010 to 29 February 2012, 368 individuals formed the study population after screening for the exclusion criteria. 77 individuals were readmitted while 291 individuals were not during the 2 year follow up period. The cumulative rehospitalization rate at 2 years was $20.9 \%$.
Concerning the socio-demographic characteristics of the study population, the median age was 76 and male to female ratio was 1 to $1.61 .98 .1 \%$ of individuals were Chinese. $47 \%$ of the study population was married, $39.7 \%$ was widowed, $7.9 \%$ was divorced or separated and $5.4 \%$ was single. For education level, $41.6 \%$ was less than primary, $31 \%$ was primary, $20.6 \%$ was secondary and only $6.8 \%$ was tertiary or above. $52.7 \%$ of the study population lived at home with family or friends, $33.7 \%$ was living in placement, $9 \%$ lived alone at home and $4.6 \%$ lived with maid at home. Regarding the clinical characteristics of the study population, the median length of inpatient stay for the study population was 27 days. The median for number of chronic physical illnesses was 2 and number of previous admissions was $0.96 .2 \%$ of individuals had non-PFU status. For the primary psychiatric diagnosis, $37.2 \%$ had cognitive disorders, $32.9 \%$ had depressive disorders, $23.1 \%$ had psychotic disorders, $4.1 \%$ had bipolar disorders and the remaining $2.7 \%$ suffered from other mental illnesses. $20.1 \%$ of the study population suffered from psychiatric comorbidities. Regarding MMSE scores, $32.3 \%$ of the study population scored $11-20,18.5 \%$ scored $21-26$, $13.6 \%$ scored less than $10,9 \%$ scored over 26 , and $26.6 \%$ did not have scores documented. $69.8 \%$ of individuals had referral to other psychiatric disciplines upon discharge. Lastly, $24.2 \%$ had history of suicidal behaviors and $15.8 \%$ had history of violence in their lifetime.

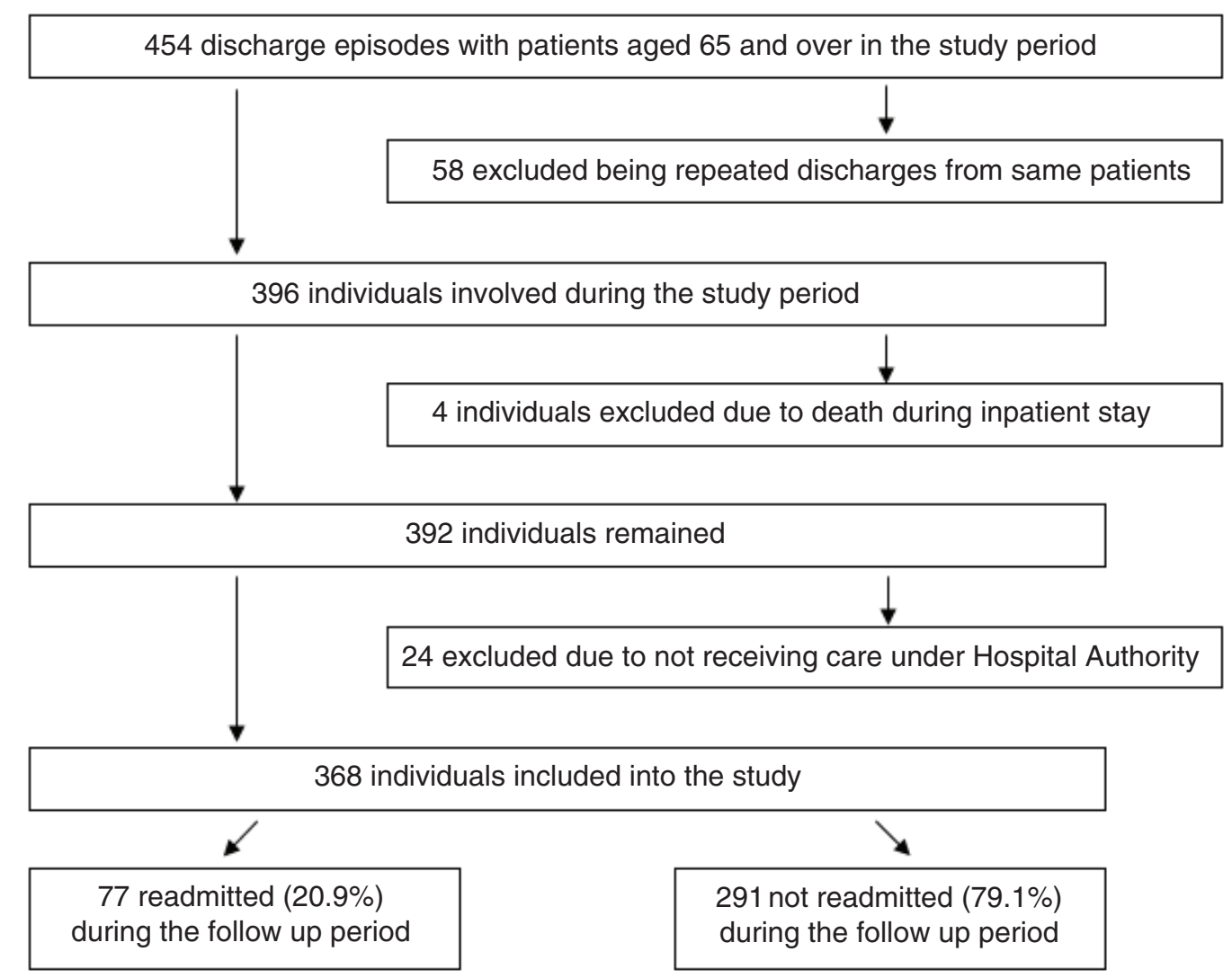

Figure 1. Formation of the study population and separation into the subgroups. 
Univariate analysis for socio-demographic factors and clinical factors of the study population are shown in Table 1 and Table 2 respectively. Results of subsequent multiple logistic regression are shown in Table 3. Four significant factors were identified with their odds ratios calculated. Referral to other psychiatric disciplines upon discharge $(\mathrm{p}<0.001, \mathrm{OR}=0.325)$ was associated with a lower risk of rehospitalization, while the other three factors including history of suicidal behaviors $(\mathrm{p}<0.001, \mathrm{OR}=4.906)$, history of violence $(\mathrm{p}<0.001, \mathrm{OR}=5.443)$ and number of previous admissions $(\mathrm{p}<0.001$, $\mathrm{OR}=1.250$ ) were associated with higher risk of rehospitalization. The overall accuracy of this predictor model was $83.4 \%$.
Survival analysis with Cox regression was then conducted to examine factors that predicted earlier rehospitalization. For individuals who did not readmit but were deceased before completion of the 2 year follow up period, the date of death was taken as the date of censoring. Taking different time points in the Kaplan-Meier survival curve as plotted in Figure 2, the cumulative readmission rate of the study population was $5.2 \%$ at 1 month, $9.5 \%$ at 3 months, $15.0 \%$ at 6 months, $17.1 \%$ at 1 year, $18.8 \%$ at 1.5 year and lastly $20.9 \%$ at 2 years upon completion of the follow up period. Most of the rehospitalization occurred within the first 6 months after discharge where the slope of the curve was steepest.

Table 1. Univariate tests for socio-demographic factors.

\begin{tabular}{|c|c|c|c|c|c|}
\hline \multirow[t]{2}{*}{ Socio-demographic Factors } & \multicolumn{2}{|c|}{$\begin{array}{l}\text { Readmitted } \\
\mathrm{N}=77\end{array}$} & \multicolumn{2}{|c|}{$\begin{array}{l}\text { Not readmitted } \\
\mathrm{N}=291\end{array}$} & \multirow{2}{*}{$\mathbf{p}$} \\
\hline & $\mathbf{n}$ & $\%$ & $\mathbf{n}$ & $\%$ & \\
\hline \multicolumn{6}{|l|}{ Gender } \\
\hline - Male & 25 & 32.5 & 116 & 39.9 & $0.235^{\circ}$ \\
\hline - Female & 52 & 67.5 & 175 & 60.1 & \\
\hline \multicolumn{6}{|l|}{ Ethnicity } \\
\hline - Chinese & 74 & 96.1 & 287 & 98.6 & 0.162 \\
\hline - Non-Chinese & 3 & 3.9 & 4 & 1.4 & \\
\hline \multicolumn{5}{|l|}{ Marital status } & $0.060^{\circ}$ \\
\hline - Widow & 24 & 31.2 & 122 & 41.9 & \\
\hline - Single & 7 & 9.1 & 13 & 4.5 & \\
\hline - Married & 36 & 46.7 & 137 & 47.1 & \\
\hline - Divorced or separated & 10 & 13.0 & 19 & 6.5 & \\
\hline \multicolumn{5}{|l|}{ Education level } & $0.627^{\circ}$ \\
\hline - Less than primary & 28 & 36.3 & 125 & 43.0 & \\
\hline - Primary & 24 & 31.2 & 90 & 30.9 & \\
\hline - Secondary & 18 & 23.4 & 58 & 19.9 & \\
\hline - Tertiary or above & 7 & 9.1 & 18 & 6.2 & \\
\hline \multicolumn{5}{|l|}{ Type of residence } & $0.353^{\circ}$ \\
\hline - Living alone & 10 & 13.0 & 23 & 7.9 & \\
\hline - Home with maid & 5 & 6.5 & 12 & 4.1 & \\
\hline - Home with family or friends & 40 & 51.9 & 154 & 52.9 & \\
\hline \multirow[t]{2}{*}{ - Living in placement } & 22 & 28.6 & 102 & 35.1 & \\
\hline & Median & IQR & Median & IQR & \\
\hline Age upon discharge (years) & 75 & $70-80.5$ & 77 & $72-83$ & $0.050^{m}$ \\
\hline
\end{tabular}

${ }^{\circ}$ Chi-squared test, 'Fisher's exact test, mMann Whitney $U$ test, IQR interquartile range 


\begin{tabular}{|c|c|c|c|c|c|}
\hline \multirow{2}{*}{ Clinical factors } & \multicolumn{2}{|c|}{$\begin{array}{l}\text { Readmitted } \\
\mathrm{N}=77\end{array}$} & \multicolumn{2}{|c|}{$\begin{array}{l}\text { Not readmitted } \\
\mathrm{N}=291\end{array}$} & \multirow{2}{*}{$\mathbf{p}$} \\
\hline & n & $\%$ & n & $\%$ & \\
\hline \multicolumn{5}{|l|}{ PFU status } & $1.000^{f}$ \\
\hline - Ordinary & 74 & 96.1 & 280 & 96.2 & \\
\hline - Target & 3 & 3.9 & 11 & 3.8 & \\
\hline \multicolumn{5}{|l|}{ Primary psychiatric diagnosis } & 0.017 \\
\hline - Cognitive disorders & 26 & 33.8 & 111 & 38.2 & \\
\hline - Depressive disorders & 18 & 23.4 & 103 & 35.4 & \\
\hline - Bipolar disorders & 3 & 3.9 & 12 & 4.1 & \\
\hline - Psychotic disorders & 29 & 37.6 & 56 & 19.2 & \\
\hline - Others & 1 & 1.3 & 9 & 3.1 & \\
\hline \multicolumn{5}{|l|}{ Psychiatric comorbidities } & $0.149^{c}$ \\
\hline - Present & 20 & 26.0 & 54 & 18.6 & \\
\hline - Absent & 57 & 74.0 & 237 & 81.4 & \\
\hline \multicolumn{5}{|l|}{ MMSE scores } & 0.518 \\
\hline - Less than 10 & 14 & 18.2 & 36 & 12.4 & \\
\hline$-11-20$ & 24 & 31.1 & 95 & 32.6 & \\
\hline$-\quad 21-26$ & 13 & 16.9 & 55 & 18.9 & \\
\hline - Over 26 & 4 & 5.2 & 29 & 10.0 & \\
\hline - Not documented & 22 & 28.6 & 76 & 26.1 & \\
\hline \multicolumn{5}{|l|}{ Referral to other disciplines } & $0.001^{c}$ \\
\hline - Yes & 42 & 54.5 & 215 & 73.9 & \\
\hline - No & 35 & 45.5 & 76 & 26.1 & \\
\hline \multicolumn{5}{|l|}{ History of suicidal behaviors } & $0.002^{\circ}$ \\
\hline - Yes & 29 & 37.7 & 60 & 20.6 & \\
\hline - No & 48 & 62.3 & 231 & 79.4 & \\
\hline \multicolumn{5}{|l|}{ History of violence } & $<0.001^{\circ}$ \\
\hline - Yes & 28 & 36.4 & 30 & 10.3 & \\
\hline \multirow[t]{2}{*}{ - No } & 49 & 63.6 & 261 & 89.7 & \\
\hline & Median & IQR & Median & IQR & \\
\hline Length of inpatient stay (days) & 30 & $17-68.5$ & 26 & $12-50$ & $0.050^{m}$ \\
\hline Number of physical illnesses & 2 & $1-4$ & 2 & $1-3$ & $0.775^{\mathrm{m}}$ \\
\hline Number of previous admissions & 1 & $0-4$ & 0 & $0-0$ & $<0.001^{\mathrm{m}}$ \\
\hline
\end{tabular}

\section{Table 3. Significant factors identified in multiple logistic regression analysis.}

\begin{tabular}{|l|l|l|l|}
\hline Factors & OR & $\mathbf{9 5 \%}$ CI & p \\
\hline Referral to other disciplines & 0.325 & $0.174-0.604$ & $<0.001$ \\
\hline History of suicidal behaviors & 4.906 & $2.357-10.212$ & $<0.001$ \\
\hline History of violence & 5.443 & $2.575-11.506$ & $<0.001$ \\
\hline Number of previous admissions & 1.250 & $1.105-1.414$ & $<0.001$ \\
\hline
\end{tabular}

Significant $\mathrm{p}<0.050, \mathrm{OR}$ odds ratio, $\mathrm{Cl}$ confidence interval Odds ratios were adjusted by gender and ethnicity 


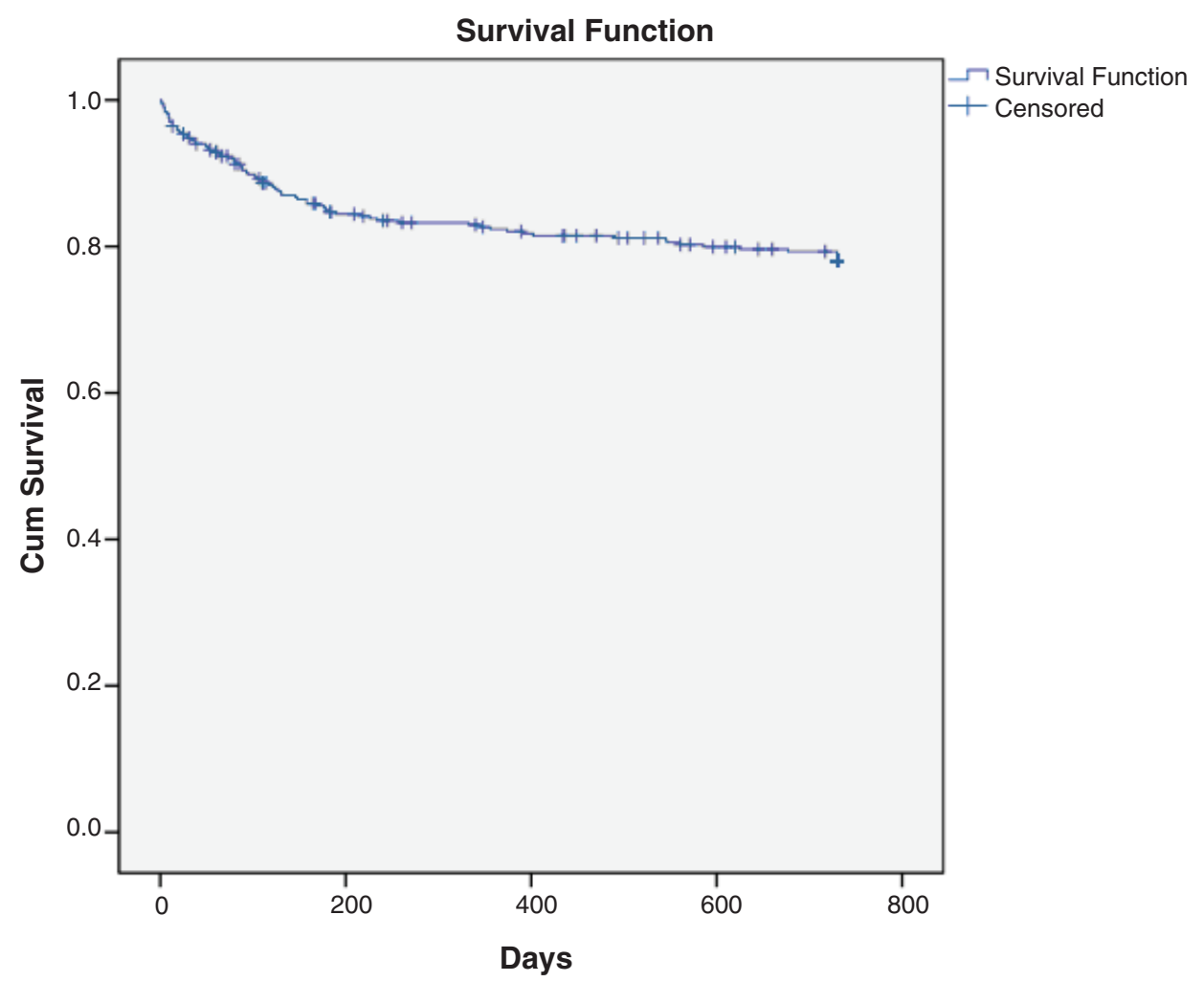

Figure 2. Kaplan-Meier survival curve for graphical representation of the data on rehospitalization.

Univariate analysis by simple Cox regression was performed and the results are shown in Table 4. The significant results of subsequent multiple Cox regression survival analyses are presented in Table 5. The same four significant factors were identified in the multiple Cox regression analysis as that in the previous logistic regression analysis. Hazard ratios were calculated and KaplanMeier survival curves were plotted. Referral to other psychiatric disciplines upon discharge $(\mathrm{p}<0.001, \mathrm{HR}=0.405)$ correlated to a longer time to rehospitalization (Figure 3 ), while history of suicidal behaviors $(p<0.001, H R=3.161)$, history of violence $(p<0.001$, $\mathrm{HR}=3.935)$ and number of previous psychiatric admissions $(\mathrm{p}<0.001$, $\mathrm{HR}=1.121$ ) were predictive factors for earlier rehospitalization (Figure 4, Figure 5, Figure 6 respectively).

\section{Discussion}

This study involved Chinese and non-Chinese elderly psychiatric patients in Hong Kong, and by comparison between the two groups, ethnicity was not identified as a significant factor. However, it should be noted that too few cases were non-Chinese and so the statistical comparison between them might not be meaningful. In comparison to other studies involving psychogeriatric patients only, most studies did not find type of residence to be a significant factor in psychiatric readmission, except 1 study $^{22}$ which reported higher
Table 4. Univariate tests with simple Cox regression in survival analysis.

\begin{tabular}{|l|l|}
\hline Socio-demographic factors & p \\
\hline Age & 0.103 \\
\hline Gender & 0.403 \\
\hline Ethnicity & 0.257 \\
\hline Marital status & 0.067 \\
\hline Education level & 0.722 \\
\hline Type of residence & 0.428 \\
\hline Clinical factors & \\
\hline Priority follow-up status & 0.996 \\
\hline Length of inpatient stay & 0.470 \\
\hline Primary psychiatric diagnosis & 0.042 \\
\hline Presence of psychiatric comorbidities & 0.193 \\
\hline Number of chronic physical illnesses & 0.662 \\
\hline Mini-mental state examination scores & 0.467 \\
\hline Referral to other disciplines & 0.001 \\
\hline History of suicidal behaviors & 0.001 \\
\hline History of violence & $<0.001$ \\
\hline Number of previous admissions & $<0.001$ \\
\hline
\end{tabular}


Table 5. Significant factors identified in multiple Cox regression analysis.

\begin{tabular}{|l|l|l|l|}
\hline Factors & HR & $\mathbf{9 5 \%} \mathbf{C l}$ & $\mathbf{p}$ \\
\hline Referral to other disciplines & 0.405 & $0.248-0.661$ & $<0.001$ \\
\hline History of suicidal behaviors & 3.161 & $1.815-5.505$ & $<0.001$ \\
\hline History of violence & 3.935 & $2.321-6.670$ & $<0.001$ \\
\hline Number of previous admissions & 1.121 & $1.052-1.195$ & $<0.001$ \\
\hline
\end{tabular}

Significant $\mathrm{p}<0.050, \mathrm{HR}$ hazard ratio, $\mathrm{Cl}$ confidence interval

Hazard ratios were adjusted by age, gender and ethnicity

readmission risk in patients with little or no supervision in living arrangements following discharge. However, this study did not find any significant differences in outcome regarding rehospitalization between patients who lived alone, with others, or in placement.

The same four clinical factors were shown to be significantly associated with rehospitalization with a $p$ value of $<0.001$ in both multiple logistic regression and Cox regression survival analysis, including referral to other psychiatric disciplines upon discharge, history of suicidal behaviors, history of violence and number of previous psychiatric admissions. With adequate aftercare services ${ }^{6,7,29,30}$ by referral to other disciplines for support upon discharge, patients were more likely to comply with treatment plans and have their problems managed in outpatient settings, which reduced the need for psychiatric rehospitalization. Moreover, a study ${ }^{12}$ had reported that patients with previous suicidal attempts were more often readmitted, and similar findings had been shown in studies that patients having violence behaviors previously were at higher risk of readmission ${ }^{11,25,28,31}$. Psychiatric rehospitalization was often required when patients displayed risks of harming self or others. Furthermore, studies had extensively reported that patients with greater number of previous admissions were predisposed to rehospitalization ${ }^{7,8,15,20,25,32,33}$. These patients might be more often rehospitalized due to suboptimal control on symptoms relating to their mental health problems and inadequate support in the community.

Concerning factors that were more specific to the elderly, 1 reviewed article $^{27}$ reported that elderly patients without medical comorbidity were more likely rehospitalized, however, number of chronic illnesses was not identified as a significant risk factor. Elderly patients were more likely to be hospitalized due to poor physical conditions. Sometimes psychiatric symptoms had already been treated in general

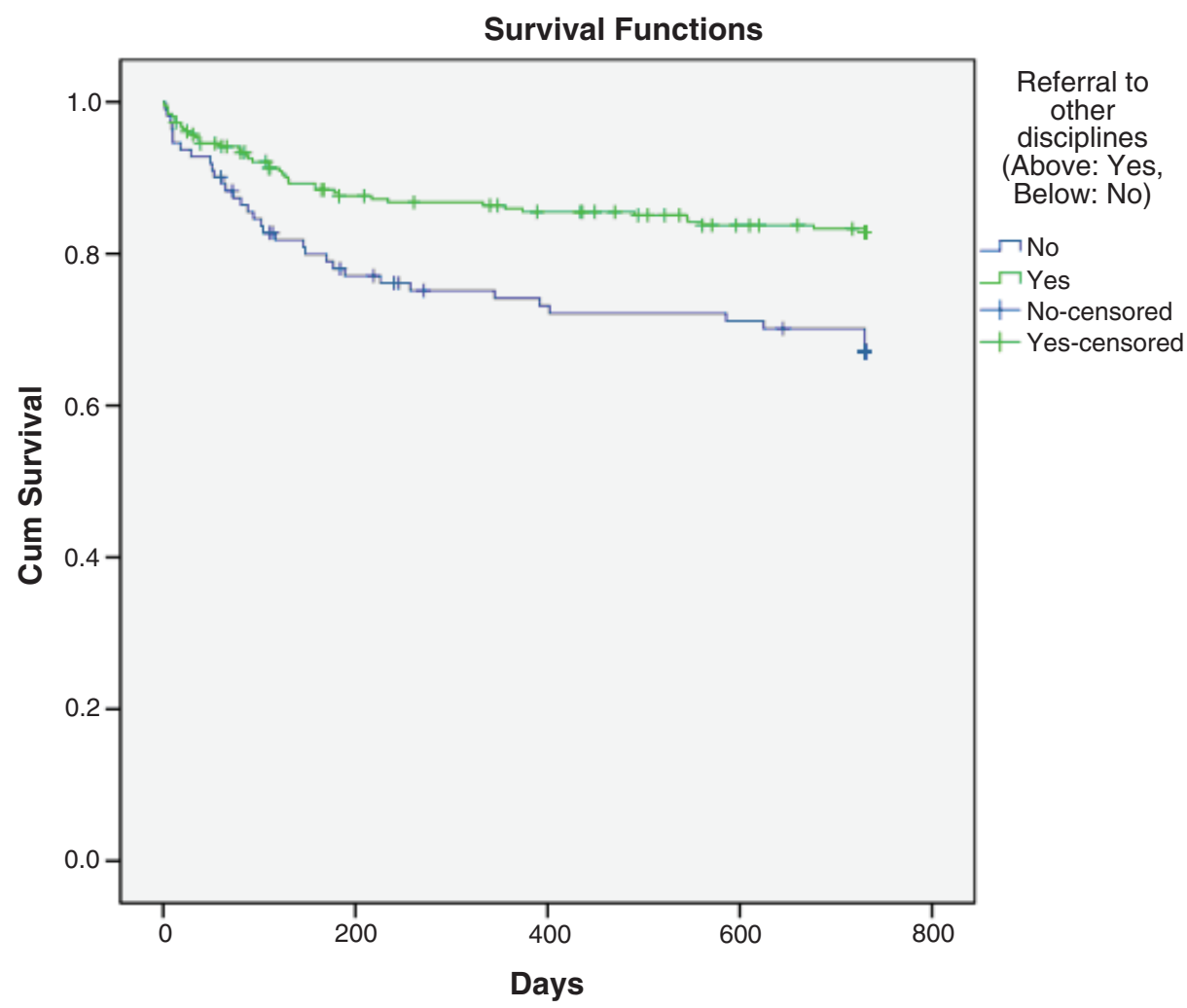

Figure 3. Kaplan-Meier survival curve showing decreased hazard of rehospitalization with referral to other psychiatric disciplines upon discharge. 


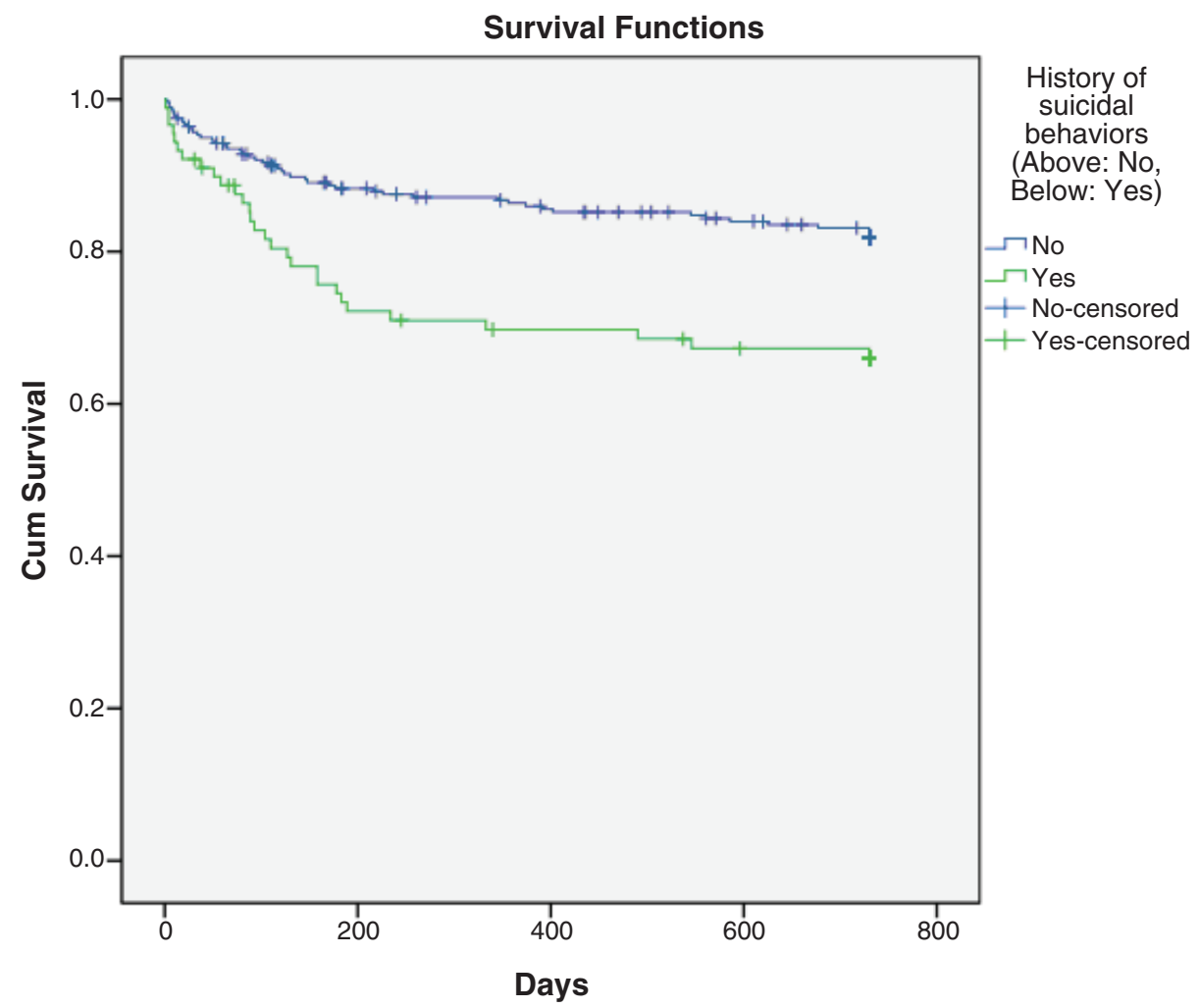

Figure 4. Kaplan-Meier survival curve showing increased hazard of rehospitalization with history of suicidal behaviors.

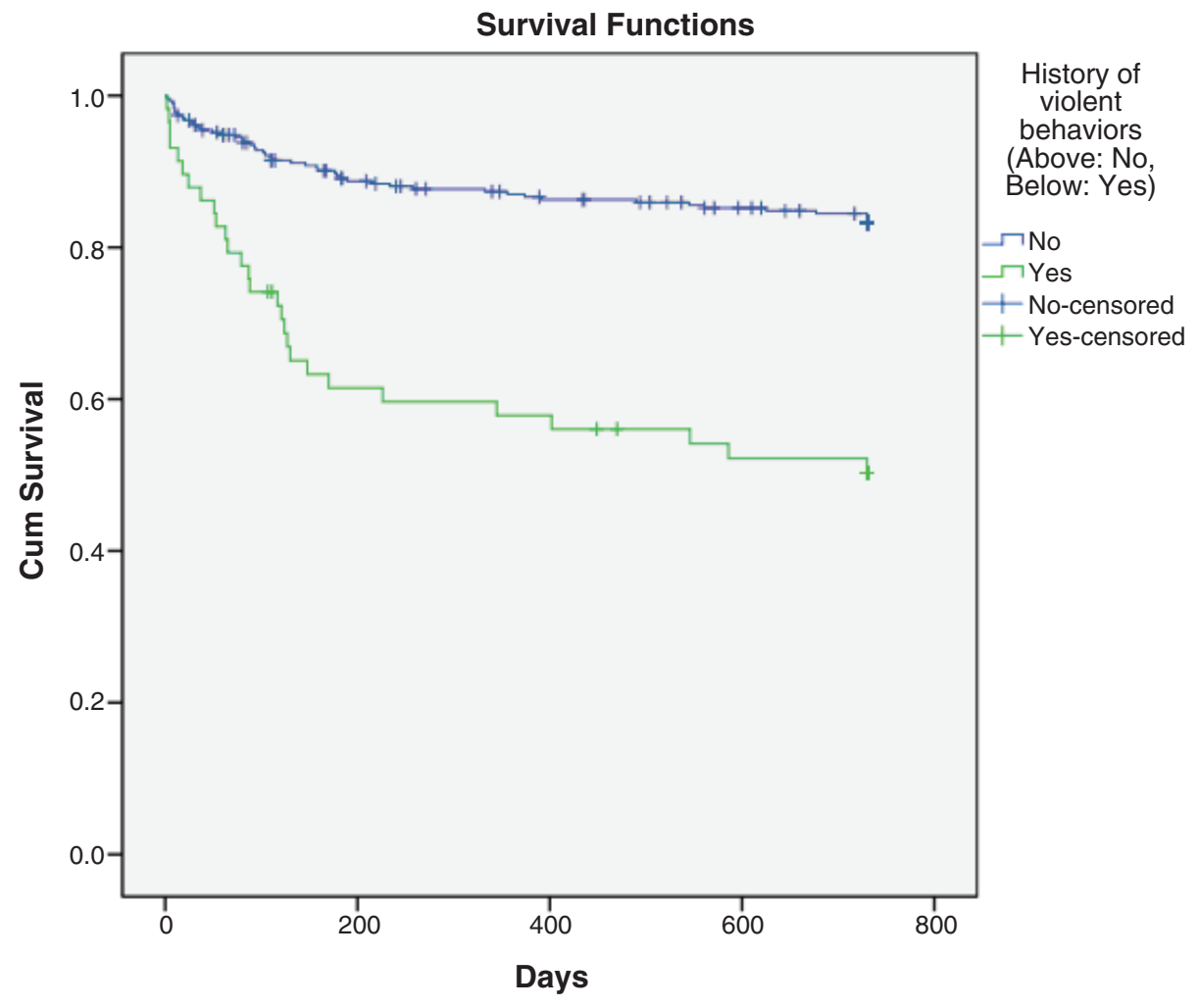

Figure 5. Kaplan-Meier survival curve showing increased hazard of rehospitalization with history of violence. 


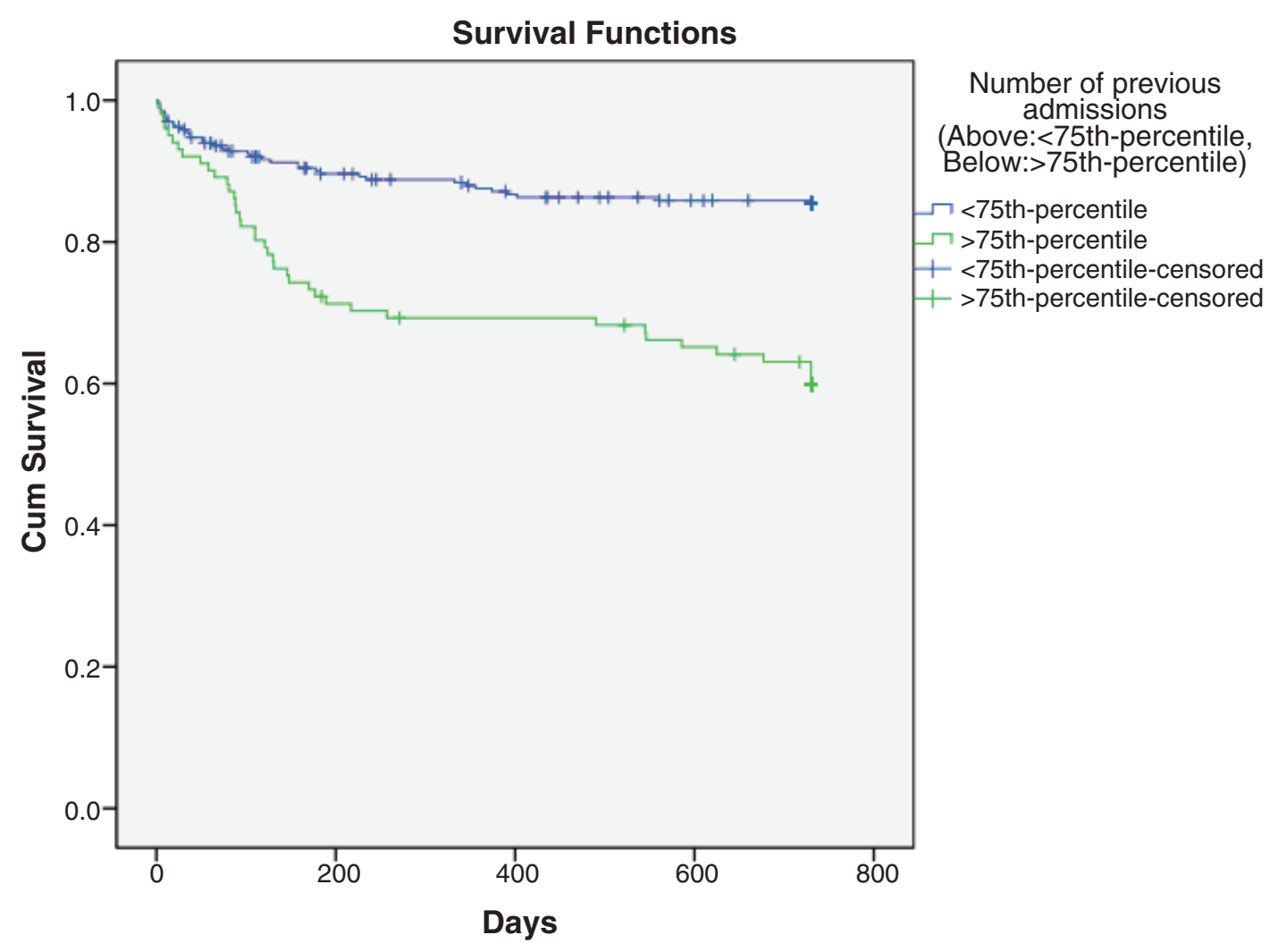

Figure 6. Kaplan-Meier curve survival curve showing increased hazard of rehospitalization with greater number of previous psychiatric admissions.

wards, but readmission to general wards were not accounted in this study. Besides, having a cognitive disorder or a lower MMSE score would not affect the risk of rehospitalization. However, it was noted that over one-fourth $(26.6 \%)$ of the study population did not have their MMSE scores documented, and therefore the results might differ if the MMSE scores from all study individuals were available.

\section{Limitations}

Firstly, this was a retrospective study and the correctness of data depended heavily on the information in CMS. Some variables could have been underestimated or changed during the follow up period. Secondly, the study population involved the psychiatric unit in a regional hospital in Hong Kong only. The findings might not be generalized to other parts of the world.

\section{Strengths}

Data on patients' characteristics were retrieved through medical records rather than self-reporting from patients and this could minimize recall bias. Besides, this study involved elderly patients only and the findings were more specific towards psychogeriatric patients.

\section{Implications}

These findings were important to the daily practice of psychiatrists and especially the psychogeriatricians, since most of the previous rehospitalization studies in the literature were not specifically targeted to elderly patients. There was very little information available regarding risk factors that predicted psychiatric rehospitalization of elderly patients in Hong Kong prior to this study. In view of the aging population and increasing need for psychiatric services in Hong Kong, this study could help in identifying elderly patients with a high rehospitalization risk for more intensive treatments and better discharge planning based on their risk factors, including history of suicidal behaviors, history of violent behaviors and greater number of previous psychiatric admissions. Factors including cognitive disorders, lower MMSE scores, comorbid chronic physical illnesses, marital status, type of residence, age, gender, ethnicity, PFU status, education level, length of inpatient stay, and presence of psychiatric comorbidities did not affect the risk of rehospitalization in the elderly psychiatric patients. On the other hand, referral to other psychiatric disciplines upon discharge was highly encouraged to prevent rehospitalization. 


\section{Future research}

A larger prospective study should be carried out to determine risk factors for psychiatric rehospitalization in elderly patients. Future research could also investigate daily functioning and quality of life of elderly patients for a better understanding on their condition after discharge from psychiatric hospitals.

\section{Conclusion}

This retrospective cohort study has provided important information regarding psychiatric rehospitalization of elderly patients. Rehospitalization was mainly affected by clinical characteristics and occurred mostly within the first 6 months after discharge. Among the significant factors for rehospitalization, history of suicidal behaviors, history of violent behaviors and greater number of previous psychiatric admissions were associated with a higher rehospitalization risk. Referral to other psychiatric disciplines upon discharge predicted a better outcome and was highly recommended for elderly patients.

\section{Data availability}

F1000Research: Dataset 1. Raw data of elderly patients discharged from psychiatric wards within the study period, 10.5256/ f1000research.7135.d103399 36

\section{Competing interests}

No competing interests were disclosed.

\section{Grant information}

The author declared that no grants were involved in supporting this work.

Acknowledgements

The author wishes to thank Dr Dunn Lai Wah, Dr Lai Xin and Dr Tsui Kwan Yee for their advice. The work was part of the dissertation for completing HKCPsych Part III Examination.

\section{Appendix}

Since 1982, mental patients in Hong Kong were categorized into non-PFU (ordinary), PFU (target) and PFU (subtarget) groups depending on their risk level. Patients in PFU (subtarget) group were considered to have the highest violence risk.

1. Fischer $\mathrm{C}$, Lingsma HF, Marang-van de Mheen $\mathrm{PJ}$, et al: Is the readmission rate a valid quality indicator? A review of the evidence. PLOS One. 2014; 9(11): e112282.

PubMed Abstract | Publisher Full Text | Free Full Text

2. Milne $\mathrm{R}$, Clarke $\mathrm{A}$ : Can readmission rates be used as an outcome indicator? BMJ. 1990; 301(6761): 1139-1140.

PubMed Abstract | Publisher Full Text | Free Full Text

3. Baron K, Hays JR: Characteristics of readmitted psychiatric inpatients. Psycho Rep. 2003; 93(1): 235-238. PubMed Abstract | Publisher Full Text

4. Chang CM, Lee $Y$, Lee $Y$, et al:: Predictors of readmission to a medicalpsychiatric unit among patients with minor mental disorders. Chang Gung Med J. 2001; 24(1): 34-43. PubMed Abstract

5. Lin $\mathrm{CH}$, Chen WL, Lin CM, et al:: Predictors of psychiatric readmissions in the short- and long-term: a population-based study in Taiwan. Clinics (Sao Paulo). 2010; 65(5): 481-489.

PubMed Abstract | Publisher Full Text | Free Full Text

6. Oiesvold T, Saarento O, Sytema S, et al.: Predictors for readmission risk of new patients: the Nordic Comparative Study on Sectorized Psychiatry. Acta Psychiatr Scand. 2000; 101(5): 367-373. PubMed Abstract | Publisher Full Text

7. Silva NC, Bassani DG, Palazzo LS: A case-control study of factors associated with multiple psychiatric readmissions. Psychiatr Serv. 2009; 60(6): 786-791. PubMed Abstract | Publisher Full Text

8. Thornicroft G, Gooch C, Dayson D: The TAPS project. 17: Readmission to hospital for long term psychiatric patients after discharge to the community. BMJ. 1992; 305(6860): 996-998.

PubMed Abstract | Publisher Full Text | Free Full Text

9. Yussuf AD, Kuranga SA, Balogun OR, et al.: Predictors of psychiatric readmissions to the psychiatric unit of a tertiary health facility in a Nigerian city - a 5-year study. Afr J Psychiatry (Johannesbg). 2008; 11(3): 187-190. PubMed Abstract | Publisher Full Text

10. Zilber N, Hornik-Lurie T, Lerner Y: Predictors of early psychiatric rehospitalization: a national case register study. Isr J Psychiatry Relat Sci. 2011; 48(1): 49-53.

PubMed Abstract

11. Dayson D, Gooch C, Thornicroft G: The TAPS project. 16: Difficult to place, long term psychiatric patients: risk factors for failure to resettle long stay patients in community facilities. BMJ. 1992; 305(6860): 993-995. PubMed Abstract | Publisher Full Text | Free Full Text

12. Tsang YKA, Wong SL: Re-hospitalization of Psychiatric Residents of a Longstay Care Home. Nurs Health. 2014; 2(6): 122-125. Reference Source

13. Wieselgren IM, Lindstrom LH: A prospective 1-5 year outcome study in firstadmitted and readmitted schizophrenic patients; relationship to heredity, premorbid adjustment, duration of disease and education level at index admission and neuroleptic treatment. Acta Psychiatr Scand. 1996; 93(1): 9-19. PubMed Abstract | Publisher Full Text

14. Woo BK, Golshan S, Allen EC, et al.: Factors associated with frequent admissions to an acute geriatric psychiatric inpatient unit. J Geriatr Psychiatry Neurol. 2006; 19(4): 226-230. PubMed Abstract | Publisher Full Text

15. Yamada MM, Korman M, Hughes CW: Predicting rehospitalization of persons with severe mental illness. J Rehabil. 2000; 66(2): 32-39. Reference Source

16. Feigon S, Hays JR: Prediction of readmission of psychiatric inpatients. Psychol Rep. 2003; 93(3 Pt 1): 816-818. PubMed Abstract | Publisher Full Text

17. Frick $\mathrm{U}$, Frick $\mathrm{H}$, Langguth $\mathrm{B}$, et al.: The revolving door phenomenon revisited: time to readmission in 17'145 [corrected] patients with 37'697 hospitalisations at a German psychiatric hospital. PLoS One. 2013; 8(10): e75612. PubMed Abstract | Publisher Full Text | Free Full Text

18. Barekatain M, Maracy MR, Hassannejad R, et al:: Factors associated with readmission of patients at a university hospital psychiatric ward in Iran. Psychiatry J. 2013; 2013: 685625. PubMed Abstract | Publisher Full Text | Free Full Text

19. Jaramillo-Gonzalez LE, Sanchez-Pedraza R, Herazo MI: The frequency of 
rehospitalization and associated factors in Colombian psychiatric patients: a cohort study. BMC Psychiatry. 2014; 14: 161.

PubMed Abstract | Publisher Full Text | Free Full Text

20. Morrow-Howell NL, Proctor EK, Blinne WR, et al:: Post-acute dispositions of older adults hospitalized for depression. Aging Ment Health. 2006; 10(4): 352-361. PubMed Abstract | Publisher Full Text

21. Irmiter C, McCarthy JF, Barry KL, et al: Reinstitutionalization following psychiatric discharge among VA patients with serious mental illness: a national longitudinal study. Psychiatr Q. 2007; 78(4): 279-286.

PubMed Abstract | Publisher Full Text

22. Mercer GT, Molinari V, Kunik ME, et al:: Rehospitalization of older psychiatric inpatients: an investigation of predictors. Gerontologist. 1999; 39(5): 591-598. PubMed Abstract | Publisher Full Text

23. Walker R, Minor-Schork D, Bloch R, et al:: High risk factors for rehospitalization within six months. Psychiatr Q. 1996; 67(3): 235-243. PubMed Abstract | Publisher Full Text

24. Manu $\mathrm{P}$, Khan $\mathrm{S}$, Radhakrishnan R, et al.: Body mass index identified as an independent predictor of psychiatric readmission. J Clin Psychiatry. 2014; 75(6): e573-577.

PubMed Abstract | Publisher Full Text

25. Tulloch AD, David AS, Thornicroft G: Exploring the predictors of early readmission to psychiatric hospital. Epidemiol Psychiatr Sci. 2015; 1-13. PubMed Abstract | Publisher Full Text

26. Bobo WV, Hoge CW, Messina MA, et al: Characteristics of repeat users of an inpatient psychiatry service at a large military tertiary care hospital. Mil Med. 2004; 169(8): 648-653.

PubMed Abstract | Publisher Full Text

27. Prince JD, Akincigil A, Kalay E, et al.: Psychiatric rehospitalization among elderly persons in the United States. Psychiatr Serv. 2008; 59(9): 1038-1045. PubMed Abstract | Publisher Full Text

28. Zhang J, Harvey C, Andrew C: Factors associated with length of stay and the risk of readmission in an acute psychiatric inpatient facility: a retrospective study. Aust N Z J Psychiatry. 2011; 45(7): 578-585.

PubMed Abstract | Publisher Full Text | Free Full Text

29. McGrew JH, Bond GR, Dietzen L, et al.: A multisite study of client outcomes in assertive community treatment. Psychiatr Serv. 1995; 46(7): 696-701. PubMed Abstract | Publisher Full Text

30. Callaly T, Hyland M, Trauer T, et al: Readmission to an acute psychiatric unit within 28 days of discharge: identifying those at risk. Aust Health Rev. 2010; 34(3): 282-285.

PubMed Abstract | Publisher Full Text

31. Kent S, Yellowlees P: Psychiatric and social reasons for frequent rehospitalization. Hosp Community Psychiatry. 1994; 45(4): 347-350. PubMed Abstract | Publisher Full Text

32. Zhou Y, Rosenheck RA, Mohamed S, et al.: Retrospective assessment of factors associated with readmission in a large psychiatric hospital in Guangzhou,

China. Shanghai Arch Psychiatry. 2014; 26(3): 138-148. PubMed Abstract | Publisher Full Text | Free Full Text

33. Monnelly EP: Instability before discharge and previous psychiatric admissions as predictors of early readmission. Psychiatr Serv. 1997; 48(12): 1584-1586.

PubMed Abstract | Publisher Full Text

34. Stoudemire A, Hill CD, Dalton ST, et al.: Rehospitalization rates in older depressed adults after antidepressant and electroconvulsive therapy treatment. J Am Geriatr Soc. 1994; 42(12): 1282-1285. PubMed Abstract | Publisher Full Text

35. Tombaugh TN, Mclntyre NJ: The mini-mental state examination: a comprehensive review. J Am Geriatr Soc. 1992; 40(9): 922-935. PubMed Abstract | Publisher Full Text

36. Wong CYT: Dataset 1 in: Predictors of psychiatric rehospitalization among elderly patients. F1000Research. 2015.

Data Source 


\section{Open Peer Review}

\section{Current Peer Review Status:}

\section{Version 1}

Reviewer Report 10 May 2016

https://doi.org/10.5256/f1000research.7685.r11435

C 2016 Braithwaite J. This is an open access peer review report distributed under the terms of the Creative Commons Attribution License, which permits unrestricted use, distribution, and reproduction in any medium, provided the original work is properly cited.

\section{Jeffrey Braithwaite}

Centre for Healthcare Resilience and Implementation Science, Australian Institute of Health Innovation, Macquarie University, Sydney, NSW, Australia

This was a useful paper and an informative read. The title is clear, although it might be indicated where the study was located (Hong Kong). I personally prefer structured abstracts.

The methods and data analysis are well described. Sensible limitations, including that the study was restricted to one psychiatric unit, are provided. The author makes the valid point that few studies of this type are about elderly patients, and this study fills a gap in our knowledge, although it is confirmatory of much that we already know in the broader domain of psychiatric rehospitalisaton.

Competing Interests: No competing interests were disclosed.

I confirm that I have read this submission and believe that I have an appropriate level of expertise to confirm that it is of an acceptable scientific standard.

Author Response 12 May 2016

Chun Yin Terry Wong, Pamela Youde Nethersole Eastern Hospital, Hong Kong, Hong Kong

Thank you very much for your review and comments.

Competing Interests: No competing interests were disclosed.

Reviewer Report 25 January 2016 
(C) 2016 Griffin W. This is an open access peer review report distributed under the terms of the Creative Commons Attribution License, which permits unrestricted use, distribution, and reproduction in any medium, provided the original work is properly cited.

\section{W.Sue T Griffin}

Department of Geriatrics, University of Arkansas for Medical Sciences, Little Rock, AR, USA

In this article, Wong and his colleagues examined several factors that might predict rehospitalization rates among elderly patients to a psychiatric unit. The study is a retrospective analysis of data from patients mostly at the Pamela Youde Nethersole Eastern Hospital in Hong Kong - possible predictive factors obtained "in part" from previous studies in the same domain were sometimes included. The reported main factors related to re-admission included a history of multiple admissions to hospital, and suicidal and or violent behaviors. It isn't surprising to note that patients with a history of suicidal or violent behaviors were at greater risk for re-admission as they require "acute" intervention (s). This is important as most re-admissions occurred in the first 6 months after discharge, raising concerns for the need for close outpatient follow up to ensure patient adherence to treatment plans. Importantly, and perhaps related to this, referral of patients to appropriate psychiatric disciplines was associated with fewer re-admissions.

It was surprising that no significant differences were noted in the study, regarding outcomes between patients who lived alone or with others. This, as well as future studies to include patients with chronic psychiatric diseases may allow discoveries regarding relationships between outcomes as they may be affected by inclusion of psychiatric symptoms in patient histories when a patient is admitted to hospital in non-psychiatric wards.

In summary, information reported in this study adds to our limited knowledge regarding the principle reasons for re-admission of elderly patients to hospital and, thus, may lead to improvements in patient care. Moreover, based on outcomes reported in this study, hospitals may benefit by relief from the usual challenges of inpatient bed availability and reimbursement from third party payers. More generally, health care costs might be reduced and family and other caregiver burdens lessened.

Competing Interests: No competing interests were disclosed.

\section{I confirm that I have read this submission and believe that I have an appropriate level of expertise to confirm that it is of an acceptable scientific standard.}

Author Response 25 Jan 2016

Chun Yin Terry Wong, Pamela Youde Nethersole Eastern Hospital, Hong Kong, Hong Kong

Thank you so much for your review and your comments.

Competing Interests: No competing interests were disclosed. 


\section{https://doi.org/10.5256/f1000research.7685.r10954}

(C) 2015 Shifu X et al. This is an open access peer review report distributed under the terms of the Creative Commons Attribution License, which permits unrestricted use, distribution, and reproduction in any medium, provided the original work is properly cited.

\section{Xiao Shifu}

Alzheimer's Diagnosis and Treatment Centre, Shanghai Jiaotong University School of Medicine, Shanghai, 200030, China

\section{Wei Li}

Alzheimer's Disease and Related Disorders Center \& Shanghai Mental Health Center, Shanghai Jiaotong University School of Medicine, Shanghai, China

We are very interested in this article, for it might be helpful in some clinical practice. However, we need the authors to answer some questions:

1. How do you select the possible factors that might be related with re-admission? Why should these preclude the factors of psychiatric drugs;

2. We suggest that the measurement data should be represented by mean and its standard deviation.

Competing Interests: No competing interests were disclosed.

\section{We confirm that we have read this submission and believe that we have an appropriate level of expertise to confirm that it is of an acceptable scientific standard.}

\section{Author Response 17 Dec 2015}

Chun Yin Terry Wong, Pamela Youde Nethersole Eastern Hospital, Hong Kong, Hong Kong

Thanks a lot for your comments. In response to your questions:

1. The possible factors included in the study were the most common predictors of psychiatric rehospitalizations that were identified from the previous studies in the literature. This study investigated if these factors could also affect the risk of rehospitalization in the Chinese elderly psychiatric patients. Since the use of different types of psychiatric drugs had not been shown to be associated with rehospitalization risk in the studies reviewed, this factor was not included as an independent variable.

2. All the continuous variables in the study were not normally distributed. Therefore median and IQR were chosen to represent these data since they would be less affected by the extreme values.

Competing Interests: No competing interestsNo competing interests 
The benefits of publishing with F1000Research:

- Your article is published within days, with no editorial bias

- You can publish traditional articles, null/negative results, case reports, data notes and more

- The peer review process is transparent and collaborative

- Your article is indexed in PubMed after passing peer review

- Dedicated customer support at every stage

For pre-submission enquiries, contact research@f1000.com 